\title{
Performance of Different Carbon
} Electrode Materials: Insights into Stability and Degradation under Real Vanadium Redox Flow Battery Operating Conditions

\author{
Journal Article \\ Author(s): \\ Nibel, Olga; Taylor, Susan M.; Pătru, Alexandra; Fabbri, Emiliana; Gubler, Lorenz; Schmidt, Thomas J. \\ Publication date: \\ 2017 \\ Permanent link: \\ https://doi.org/10.3929/ethz-b-000190702 \\ Rights / license: \\ Creative Commons Attribution 4.0 International \\ Originally published in: \\ Journal of the Electrochemical Society 164(7), https://doi.org/10.1149/2.1081707jes
}




\title{
Performance of Different Carbon Electrode Materials: Insights into Stability and Degradation under Real Vanadium Redox Flow Battery Operating Conditions
}

\author{
Olga Nibel, ${ }^{\mathrm{a},=}$ Susan M. Taylor, ${ }^{\mathrm{a},=, *}$ Alexandra Pătru, ${ }^{\mathrm{a}, * *, \mathrm{z}}$ Emiliana Fabbri, ${ }^{\mathrm{a}}$ \\ Lorenz Gubler, ${ }^{\text {a,** }}$ and Thomas J. Schmidt ${ }^{\mathrm{a}, \mathrm{b}, * *}$ \\ ${ }^{a}$ Electrochemistry Laboratory, Paul Scherrer Institut, 5232 Villigen PSI, Switzerland \\ ${ }^{b}$ Laboratory of Physical Chemistry, ETH Zurich, 8093 Zurich, Switzerland
}

\begin{abstract}
This work focuses on the performance and stability of selected commercial carbon electrode materials before and after heat-treatment in an operating all-vanadium redox flow battery (VRB). Heat treatment results in improved cell performance for all tested materials, with SGL 39 AA carbon papers and SIGRACELL GFD4.6 EA carbon felt showing the best performance. Further investigation of these two materials by in situ reference electrode measurements reveal improvements after heat-treatment that originate mainly from the negative electrode or $\mathrm{V}^{2+} / \mathrm{V}^{3+}$ side of the cell. Upon extended cycling, carbon felt is found to be stable. Carbon papers however, show significant performance losses originating from the negative electrode side. The potential limit during charging and the exposure to very negative potentials appears to be a critical issue at the negative electrode in the VRB. Analysis of both materials after cycling by scanning electron microscopy, Raman spectroscopy and X-ray photoelectron spectroscopy reveal significant differences in their surface chemistry, structure and morphology. These differences give valuable insights into the behavior and degradation of different carbon materials used in VRBs.

(C) The Author(s) 2017. Published by ECS. This is an open access article distributed under the terms of the Creative Commons Attribution 4.0 License (CC BY, http://creativecommons.org/licenses/by/4.0/), which permits unrestricted reuse of the work in any medium, provided the original work is properly cited. [DOI: 10.1149/2.1081707jes] All rights reserved.

(cc) BY
\end{abstract}

Manuscript submitted March 6, 2017; revised manuscript received April 28, 2017. Published June 2, 2017.

Redox flow batteries (RFBs) are a promising technology for efficient energy storage and grid stabilization. ${ }^{1,2}$ The all-vanadium redox flow battery (VRB), which uses vanadium ions in different oxidation states at the positive and negative electrodes, is the most advanced RFB to date. ${ }^{3}$ The electrodes are a crucial component of the VRB, as they provide the surface on which the respective electrochemical reactions occur. Thus, catalytic activity, wettability and mass transport properties of the electrodes strongly affect VRB performance. Ideal electrodes for the VRB should provide both: long term durability and stable catalytic activity. Various materials have been considered as electrodes for the use in VRBs including non-carbon based dimensionally stable anode electrodes and carbon based electrodes such as carbon felt, carbon paper, carbon nanotubes, carbon nanofibers or graphene oxides. ${ }^{4}$ To enhance electrochemical activity and wettability of carbon based materials in VRBs, different surface modification methods have been used. Carbon electrodes have been coated with metals such as iridium, ${ }^{5}$ doped with nitrogen ${ }^{6}$ or decorated with nanomaterials such as graphene-nanowalls ${ }^{7}$ or graphite carbon nanotubes. ${ }^{8}$ Recently, Zhou et al. reported activation of carbon papers and carbon cloth by heat-treatment and subsequent etching with $\mathrm{KOH} .{ }^{9,10}$ The performance of carbon materials have also been shown to be improved by means of thermal, ${ }^{11-13}$ chemical, ${ }^{14,15}$ electrochemical, ${ }^{16}$ plasma ${ }^{17}$ or a combination of corona discharge and hydrogen peroxide treatment. ${ }^{18}$

Most of these surface treatment approaches introduce functional groups, commonly oxygen onto the carbon electrode surface. This leads to increased wettability and redox activity, which is generally attributed to the increased concentration of surface-active oxygen functional groups. ${ }^{11}$ Among the various surface modifications, heattreatment is still regarded as the most common and facile approach to incorporate oxygen groups onto the surface of carbon materials. ${ }^{4}$ In an effort to better understand the role of oxygen functional groups on electrode performance, Fink et al. studied pristine and heat-treated Rayon (a regenerated cellulose fiber) based GFA carbon felt and a polyacrylonitrile (PAN) based GFD carbon felt. According to this study, the normalized rate constant for the $\mathrm{V}^{2+} / \mathrm{V}^{3+}$ redox reaction increased with increasing number of oxygen functional groups, the rate constant for the $\mathrm{VO}^{2+} / \mathrm{VO}_{2}{ }^{+}$redox reaction decreased for both types

\footnotetext{
$=$ These authors contributed equally to this work.

*Electrochemical Society Student Member.

**Electrochemical Society Member.

${ }^{\mathrm{z}}$ E-mail: alexandra.patru@psi.ch
}

of carbon felt electrodes. ${ }^{19}$ Miller et al. demonstrated that the introduction of oxygen containing functionalities enhances the kinetics of $\mathrm{V}^{2+} / \mathrm{V}^{3+}$ and inhibits the kinetics of $\mathrm{VO}^{2+} / \mathrm{VO}_{2}{ }^{+} .{ }^{20}$ Similar observations were made in a study by our group, where oxygen groups alone were not found to play a crucial role in the activity of glassy carbon electrodes for vanadium (V) reduction. However, surface modification leading to increased roughness and number of defects appeared to play a positive role for this reaction. ${ }^{21}$ Many recent studies focusing on both vanadium redox reactions involved in the VRB have shown that the overpotential associated with the negative half-cell dominates the voltage losses of the VRB and limits performance..$^{22-25}$

Many efforts have been successfully undertaken to improve the electrochemical activity of various carbon materials, which result in better VRB performance. However, despite these improvements, some of the modified carbon materials are not suitable for use in the VRB because of their poor operational lifespan. The use of heat treated carbon materials such as Rayon based carbon felt GFA6 or PAN based carbon papers SGL 10 AA resulted in an initial performance increase in the VRB. However, the cycling stability of both modified carbon electrodes was found to be very poor, with electrodes losing their initial activity after a number of charge/discharge cycles. ${ }^{23,26}$

In this study, the performance of a set of commercial carbon materials before and after heat-treatment is investigated in a commercial VRB test system. The two best performing materials were selected and studied in more detail. Reference electrode measurements were used to decouple the positive and negative reaction contributions to the overall performance. Cycling stability of the two selected materials was investigated over an extended period. The materials were characterized by X-ray photoelectron spectroscopy (XPS), Raman spectroscopy and scanning electron microscopy (SEM) before and after cycling. Valuable insights into the limiting reaction of this system and the differing stabilities of two carbon based materials are discussed.

\section{Experimental}

Electrode materials and preparation.-Four commercial PAN based carbon materials were used in this work: SGL 39 AA carbon papers (thickness: $\sim 280 \mu \mathrm{m}$ ), SGL 10 AA carbon papers (thickness: $\sim 360 \mu \mathrm{m}$ ), Toray carbon papers TGP-H-120 (thickness: $\sim 370 \mu \mathrm{m}$ ) and SGL SIGRACELL GFD4.6 EA carbon felt electrodes (thickness: $\sim 4300 \mu \mathrm{m})$. The heat-treatment (HT) was carried out according to 
the procedure described in the literature. ${ }^{13}$ The carbon electrodes were placed in a tube furnace at $400^{\circ} \mathrm{C}$ under a steady flow of synthetic air $\left(30 \mathrm{~mL} \mathrm{~min}^{-1}\right)$ for 30 hours. HT has been used to denote heat treated materials throughout the text.

Cell architecture and electrolyte preparation.-A commercial redox flow test system (Model 857, Scribner) with an active area of 25 $\mathrm{cm}^{2}$, serpentine flow fields and a Nafion 117 membrane was used. Nafion 117 was pretreated at $80^{\circ} \mathrm{C}$ in $32 \%$ nitric acid for $1 \mathrm{~h}$, followed by rinsing and boiling for $1 \mathrm{~h}$ in water. ${ }^{27} 1 \mathrm{M}$ vanadium solution was prepared by dissolving $\mathrm{VOSO}_{4} \cdot n \mathrm{H}_{2} \mathrm{O}$ (Alfa Aesar, 99.9\% purity, where $n$ was determined to be 3 by thermogravimetric analysis) in 2 $\mathrm{M} \mathrm{H}_{2} \mathrm{SO}_{4}$. The solutions were charged following a typical protocol and considered fully charged (100\% state of charge, SoC) at a current density of $2 \mathrm{~mA} \mathrm{~cm}^{-2} .^{28}$

Three layers of SGL 10 AA carbon papers was identified previously as the optimum number for best performance in a VRB and this number was used here. ${ }^{12}$ To maintain the same thickness of layered carbon papers in the cell, three Toray TGP-H-120 and four SGL 39 AA papers were used on either side of the cell. One piece of carbon felt (GFD6.4 EA) was used on either side of the cell.

Polarization curves and reference electrode measurements.-Discharge polarization curves were recorded galvanostatically with freshly charged electrolytes $(100 \% \mathrm{SoC})$ at an electrolyte flow rate of $30 \mathrm{~mL} \mathrm{~min}{ }^{-1}$. A single-pass method was used to measure polarization curves, whereby no recirculation of the electrolyte into the storage tanks occurred and the discharged electrolyte was collected externally. This ensured a $100 \%$ SoC electrolyte entered the cell throughout the experiment. Data points were measured at current densities of 0,20 , $40,60,100,140,180,220,260 \mathrm{~mA} \mathrm{~cm}^{-2}$ holding for 20 seconds at each point. The current limit of this system was $280 \mathrm{~mA} \mathrm{~cm}{ }^{-2}$. A $\mathrm{Hg} / \mathrm{Hg}_{2} \mathrm{SO}_{4}$ reference electrode (C3 Prozess - und Analysentechnik $\mathrm{GmbH}$ ) was connected to the cell in an 'edge-type' configuration in which an extension of the Nafion 117 membrane was placed in contact with the reference electrode used in the cell..$^{29-31}$ The junction region was kept hydrated with a $2 \mathrm{M} \mathrm{H}_{2} \mathrm{SO}_{4}$ solution.

Charge/discharge cycling.-Charge/discharge cycling was carried out at $30^{\circ} \mathrm{C}$, with a flow rate of $30 \mathrm{~mL} \mathrm{~min}^{-1}$ at current density of 40 $\mathrm{mA} \mathrm{cm}{ }^{-2}$ using $70 \mathrm{~mL}$ of $1 \mathrm{M}$ vanadium electrolyte at each side of the cell (poor performance of pristine carbon felt required a reduced current density of $20 \mathrm{~mA} \mathrm{~cm}{ }^{-2}$ ). The upper and lower cell potential cutoff limits were set to $1.7 \mathrm{~V}$ and $0.8 \mathrm{~V}$ respectively. Coulombic efficiency (CE), voltage efficiency (VE) and energy efficiency (EE) were calculated from the $2^{\text {nd }}$ cycle following a procedure in the literature. ${ }^{32}$ Extended cycling stability of selected heat treated materials (HT-SGL 39 AA and HT-GFD6.4 EA) was carried out with $100 \mathrm{~mL}$ of $1 \mathrm{M}$ vanadium electrolyte at each side of the cell, 35 charge/discharge cycles at $100 \mathrm{~mA} \mathrm{~cm}^{-2}$ and an additional 38 cycles at $120 \mathrm{~mA} \mathrm{~cm}^{-2}$ were measured under the same conditions described previously.

$X$-ray photoelectron spectroscopy (XPS).-X-ray photoelectron spectroscopy (XPS) was used determine the total oxygen content $(\mathrm{O} / \mathrm{C}$ ratio) and identify the different oxygen groups on the surface of the carbon materials. Samples of pristine and freshly heat treated GFD4.6 EA and SGL 39 AA were analyzed as well as HT-GFD4.6 EA and HT-SGL 39 AA after extended cycling. As a comparison for the cycled materials, HT-GFD4.6 EA and HT-SGL 39 AA electrodes were each soaked in $2 \mathrm{M} \mathrm{H}_{2} \mathrm{SO}_{4}$ solution for a week (duration of a typical cycling experiment) to evaluate the influence of sulfuric acid alone on the oxygen content of the electrodes. Electrodes were rinsed thoroughly using deionized water and dried before being analyzed by XPS. A VG ESCALAB 220iXL spectrometer (Thermo Fischer Scientific) equipped with an $\mathrm{Al} \mathrm{K} \alpha$ monochromatic source and a magnetic lens system was used. High resolution spectra of the $\mathrm{C} 1 \mathrm{~s}$ and $\mathrm{O} 1 \mathrm{~s}$ peaks were used to determine the surface oxygen to carbon ratio $(\mathrm{O} / \mathrm{C}$ ratio) for all electrode samples. All curves were fitted according to a Gaussian-Lorentzian function. Background subtraction was performed according to the Shirley method, and the atomic sensitivity factors (ASF) of Scofield were applied to estimate the atomic composition. Deconvolution of the $\mathrm{C} 1 \mathrm{~s}$ core level spectra was carried out fitting the following peaks: $284.1 \mathrm{eV}, 284.9 \mathrm{eV}, 285.96 \mathrm{eV}, 288.2$ $\mathrm{eV}, 290.4 \mathrm{eV}$ and $291.61 \mathrm{eV}( \pm 0.8 \mathrm{eV})$ arising from C-C, C-H, C-OR (including $\mathrm{C}-\mathrm{OH}$ and $\mathrm{O}-\mathrm{C}-\mathrm{O}$ ), $\mathrm{C}=\mathrm{O}, \mathrm{COOH}$ and shakeup satellite contributions, respectively. ${ }^{33,34}$

Raman spectroscopy.-A Raman microscope (Labram HR800 Horiba-Jobin Yvon, Japan) with a He-Ne laser $(632.8 \mathrm{~nm})$ and a $50 \times$ objective (ULWDMS Plan 50, NA $=0.55$, Olympus, Japan) was used to investigate the near-to-surface region of both untreated and heat treated SGL 39 AA carbon papers and GFD4.6 EA carbon felt electrodes and HT-SGL 39 AA and HT-GFD4.6 EA electrodes after cycling. The measurements were performed with a grating of 600 line $\mathrm{mm}^{-1}$ and a laser power of $20 \mathrm{~mW}$. First order Raman spectra were recorded in the range 1000 to $2000 \mathrm{~cm}^{-1}$.

Scanning electron microscopy (SEM).-The surface morphology of carbon materials was analyzed by scanning electron microscopy (SEM). SEM images were taken using a FESEM Ultra 55 from Carl Zeiss with an acceleration voltage of $2 \mathrm{keV}$.

\section{Results and Discussion}

Performance of carbon materials before/after heat-treatment.The performance of four pristine, commercially available carbon electrode materials was studied in an operating VRB cell. The effect of heat-treatment on these materials was investigated. Carbon felt electrodes (GFD4.6 EA) that are widely used in VRBs were compared to various carbon papers including SGL 10 AA, SGL 39 AA and Toray TGP-H-120. Figure 1 shows the polarization curves measured for the untreated and heat treated materials and the key performance indicators for these materials are summarized in Table I.

Among the untreated materials, the SGL 39 AA carbon papers showed the best performance (Figure 1a). After heat-treatment, all electrode materials showed an improvement in overall cell performance. The HT-GFD4.6 EA carbon felt and HT-SGL 39 AA carbon papers showed the best performance of all heat treated materials tested in this study (Figure 1b).

Untreated SGL 39 AA showed the highest energy efficiency (68\%) and discharge capacity (59\%) for the pristine materials. Carbon felt showed the worst performance, even at a reduced current density (20 $\mathrm{mA} \mathrm{cm}{ }^{-2}$ ) a very low energy efficiency (48\%) and discharge capacity $(34 \%)$ was observed. After heat-treatment the HT-SGL 39 AA carbon papers and HT-GFD4.6 EA carbon felt showed the highest energy efficiencies of $79 \%$ and $81 \%$ respectively of all the heat treated materials. (See the Supplementary Information for further details related to cycling history with various untreated and heat treated carbon electrodes (Figure S1)). These materials were selected for further investigation and will be the focus of the remainder of this work

Polarization curves with reference electrode.-A reference electrode included in the operating system allowed the decoupling of the contributions of the positive and negative electrode reactions to the overall performance. Figures $2 \mathrm{a}$ and $2 \mathrm{~b}$ show the polarization curves for both carbon paper and carbon felt before and after heat-treatment and illustrate the overpotential contributions from both the positive and negative electrode reactions.

The observed improvements after heat-treatment originate from the negative electrode side for both materials. The $\mathrm{V}^{2+} / \mathrm{V}^{3+}$ redox reaction appears to benefit significantly after heat-treatment of the electrode materials. This observation is in line with several previous studies. $^{20,22-24,35}$ The positive half-cell does not show any significant changes in overpotential before and after heat-treatment of the electrode materials.

Cycling stability.-Cycling stability of HT-GFD6.4 EA carbon felt and HT-SGL 39 AA carbon papers was investigated under VRB 

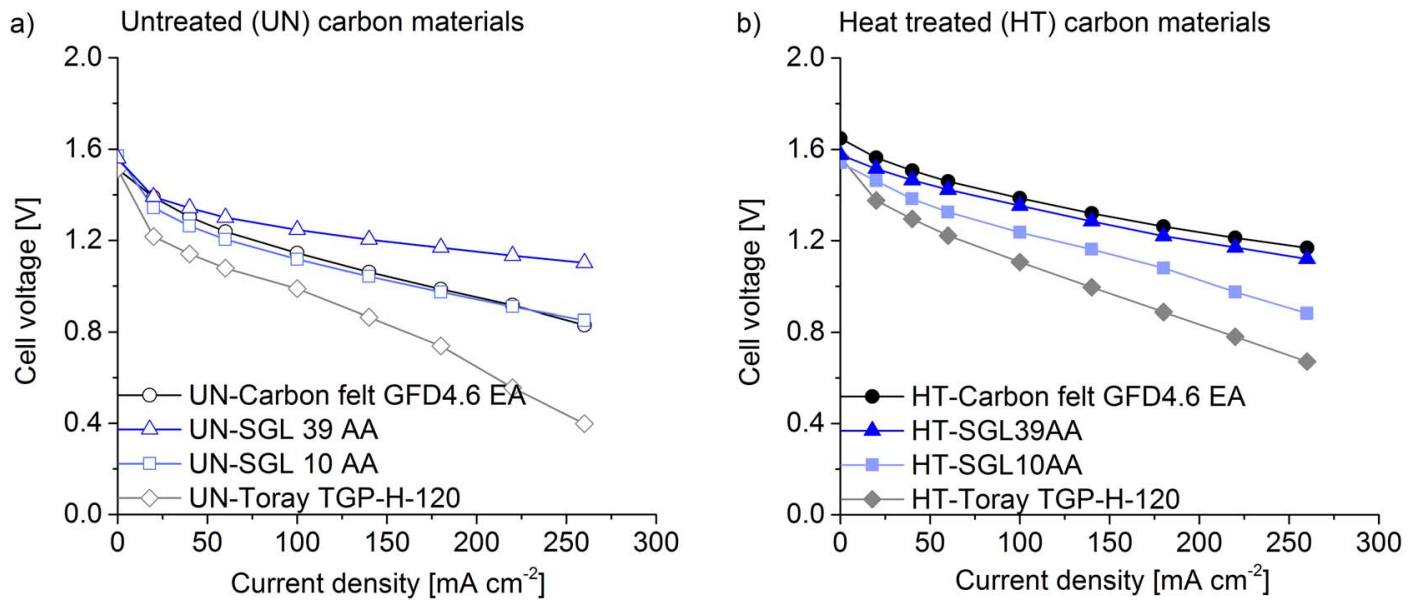

Figure 1. Discharge polarization curves measured in an operating VRB (SoC: $100 \%$ ) with a) untreated and b) heat treated commercial carbon electrode materials.

Table I. Key performance indicators for untreated and heat treated carbon materials. Coulombic efficiency (CE), voltage efficiency (VE), energy efficiency $(E E)$ and discharge capacity $\left(C_{\text {dis }}\right)$ determined from the $2^{\text {nd }}$ cycle at $40 \mathrm{~mA} \mathrm{~cm}{ }^{-2}\left(20 \mathrm{~mA} \mathrm{~cm}^{-2}\right.$ in case of untreated carbon felt*).

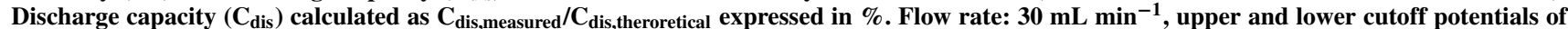
$1.7 \mathrm{~V}$ and $0.8 \mathrm{~V}$ respectively.

\begin{tabular}{|c|c|c|c|c|c|c|c|c|}
\hline \multirow[b]{2}{*}{$\begin{array}{c}\text { Sample } \\
{[-]}\end{array}$} & \multicolumn{4}{|c|}{ untreated carbon materials } & \multicolumn{4}{|c|}{ heat treated carbon materials } \\
\hline & $\begin{array}{l}\mathrm{CE} \\
{[\%]}\end{array}$ & $\begin{array}{l}\mathrm{VE} \\
{[\%]}\end{array}$ & $\begin{array}{l}\mathrm{EE} \\
{[\%]}\end{array}$ & $\begin{array}{l}\mathrm{C}_{\mathrm{dis}} \\
{[\%]}\end{array}$ & $\begin{array}{c}\mathrm{CE} \\
{[\%]}\end{array}$ & $\begin{array}{l}\mathrm{VE} \\
{[\%]}\end{array}$ & $\begin{array}{l}\mathrm{EE} \\
{[\%]}\end{array}$ & $\begin{array}{l}\mathrm{C}_{\mathrm{dis}} \\
{[\%]}\end{array}$ \\
\hline Toray TGP-H-120 & 42 & 59 & 25 & 13 & 89 & 68 & 61 & 56 \\
\hline SIGRACET SGL 39 AA & 91 & 75 & 68 & 59 & 91 & 87 & 79 & 79 \\
\hline SIGRACET SGL 10 AA & 87 & 73 & 64 & 53 & 92 & 79 & 73 & 71 \\
\hline SIGRACELL GFD4.6EA & $88^{*}$ & $54^{*}$ & $48^{*}$ & $34^{*}$ & 92 & 88 & 81 & 88 \\
\hline
\end{tabular}

operating conditions. At the high current densities (100 and $120 \mathrm{~mA}$ $\mathrm{cm}^{-2}$ ), HT-GFD6.4 EA carbon felt showed superior cycling performance, including higher VE and charge/discharge capacity. However both systems experienced slight VE decreases and significant capacity fading during the cycling experiments, this effect was more pronounced for HT-SGL 39 AA carbon papers (Figure 3). In general, capacity fading and decrease in VE during cycling experiments can be explained by two reasons: (1) as a result of high vanadium cross-over through the Nafion 117 membrane and/or (2) as a result of electrode degradation under VRB operating conditions. To separate the effect of electrolyte cross-over and possible electrode degradation, the vanadium electrolyte was replaced after cycling with a fresh electrolyte and the cell was charged and discharged again. If capacity or
VE decline was solely a consequence of electrolyte imbalance caused by cross-over through the membrane, replacement of the imbalanced electrolyte should allow the restoration of the original cycling performance observed before the cycling experiments. If however electrolyte imbalance was accompanied by electrode degradation, it would not be possible to restore the original cycling performance by replacing the electrolyte with a fresh one.

In the case of HT-GFD6.4 EA carbon felt, the use of fresh electrolyte allowed the full recovery of the original cycling performance (Figure 3d). Only a very small decrease in discharge capacity (2\%) and VE $(2 \%)$ was observed. In this case the losses observed during cycling were associated only with electrolyte imbalance and not with carbon felt degradation. In contrast to this, the original cell
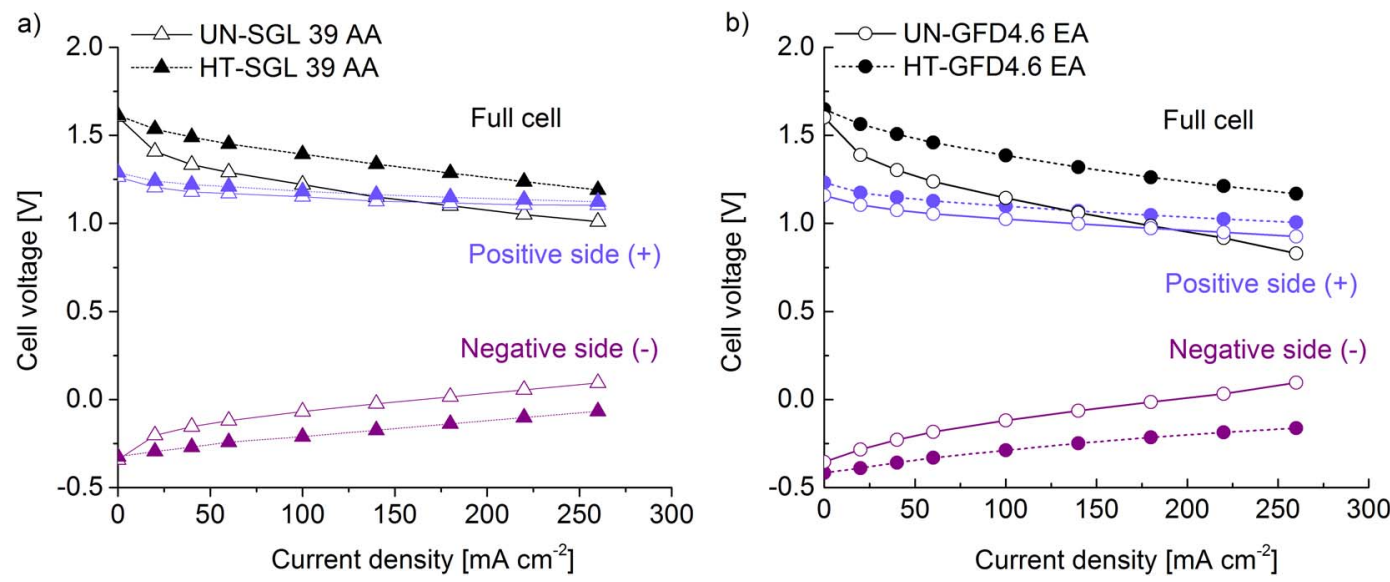

Figure 2. Discharge polarization curves (SoC: 100\%) for untreated and heat treated a) SGL 39 AA carbon papers and b) GFD4.6 EA carbon felt showing contributions from the positive and negative reactions to the overall full cell voltage. 

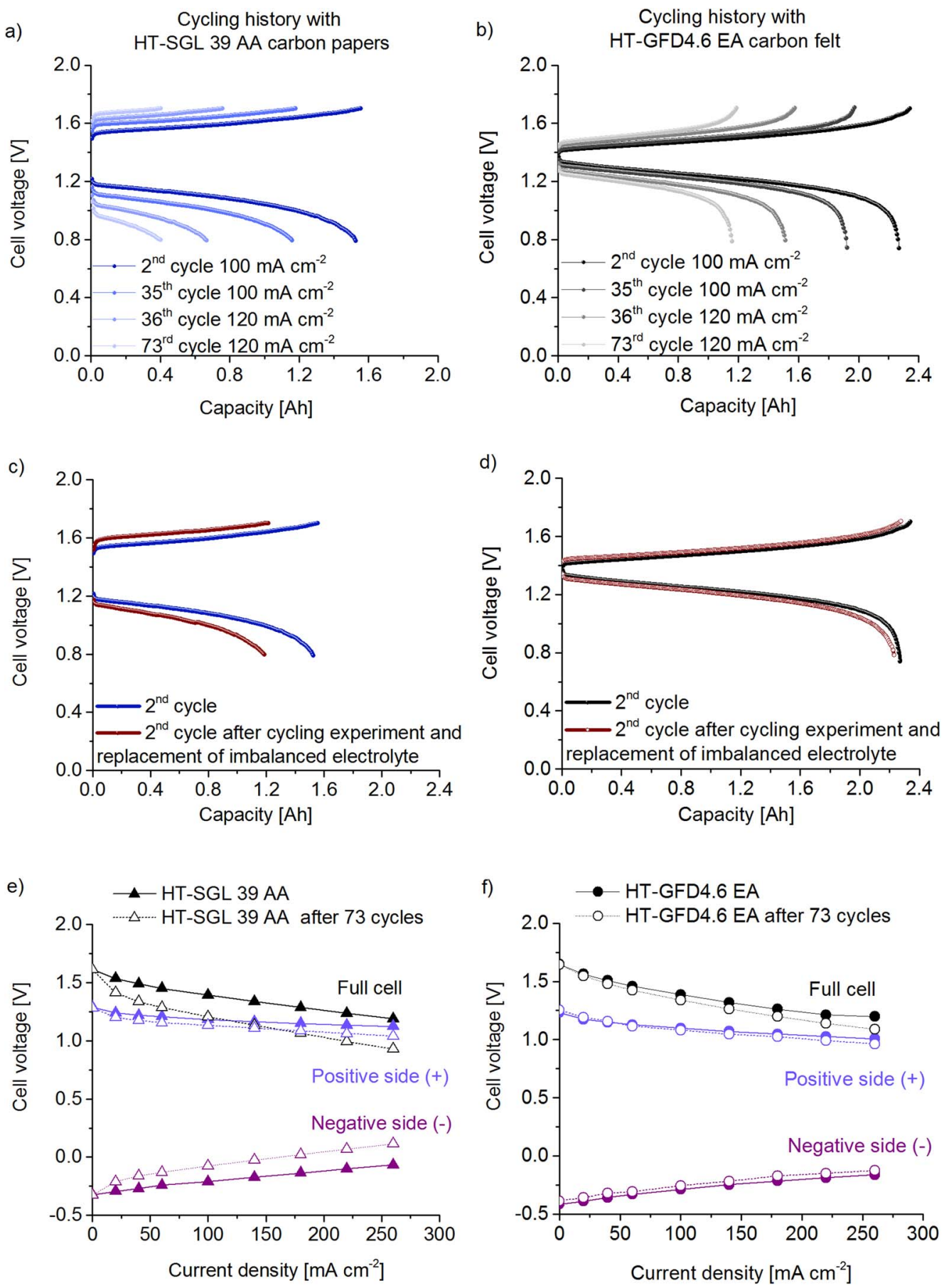

Figure 3. Cycling history for a) HT-SGL 39 AA carbon papers b) HT-GFD4.6 EA carbon felt; Cycling performance of the cell in the $2^{\text {nd }}$ cycle of long term experiment and in the $2^{\text {nd }}$ cycle after replacement of imbalanced electrolyte for c) HT-SGL 39 AA carbon papers d) HT-GFD4.6 EA carbon felt; Polarization curves measured before and after 73 cycles (with freshly prepared electrolyte) as well as corresponding changes on the positive and negative side for (e) HT-SGL 39 AA carbon papers (f) HT-GFD4.6 EA carbon felt.

performance could not be restored for HT-SGL 39 AA carbon papers upon replacement of the electrolyte (Figure 3c). Discharge capacity decreased by $22 \%$ and VE by $4 \%$. This is an indication that the performance decline is not only associated with electrolyte imbalance but also with electrode degradation. Polarization curves measured after extended cycling support these observations. The HT-GFD6.4 EA carbon felt showed almost no change in overall performance before and after cycling (Figure 3f). However, a significant performance loss was observed for HT-SGL 39 AA carbon papers after cycling
(Figure 3e). The performance loss originated mainly from the negative electrode side.

Although both carbon materials were activated using the same heat-treatment method, HT-GFD4.6 EA carbon felt showed superior cycling stability compared to HT-SGL 39 AA carbon papers under VRB operating conditions. Other studies in the literature have reported poor stabilities of heat treated SGL 10AA carbon papers and GFA6 carbon felt. ${ }^{23,26}$ Following these observations, the surface properties of the stable and unstable electrode materials before and after extended 


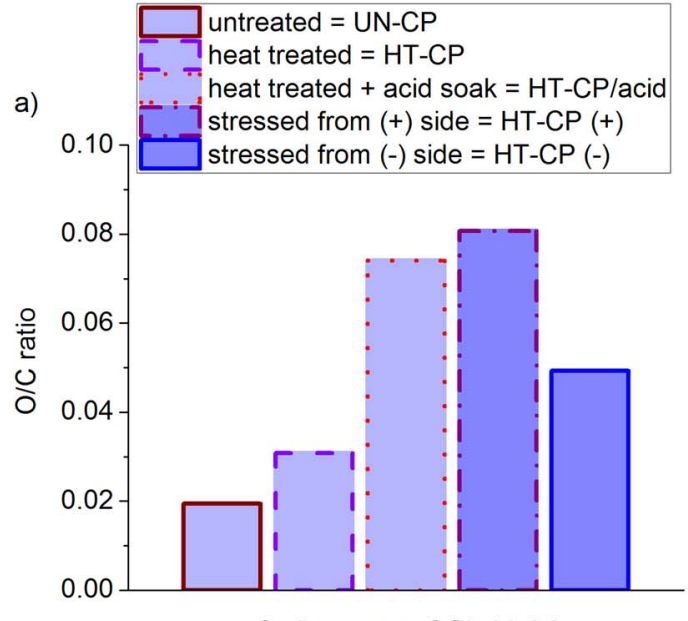

c)
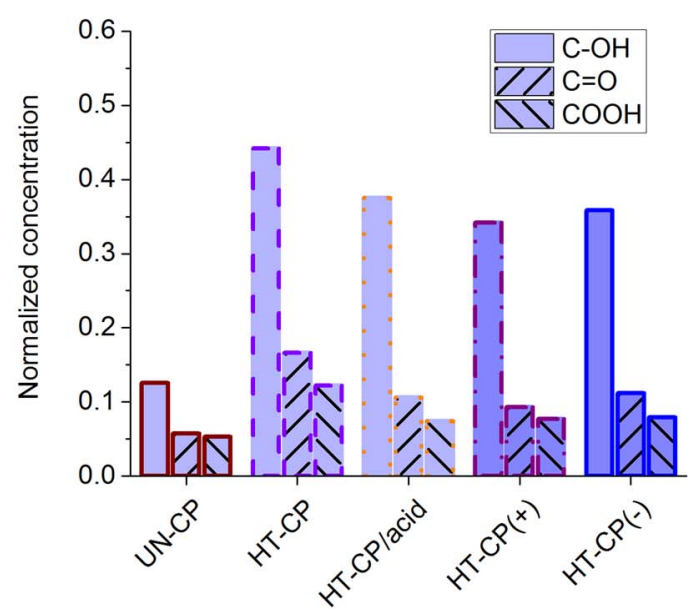

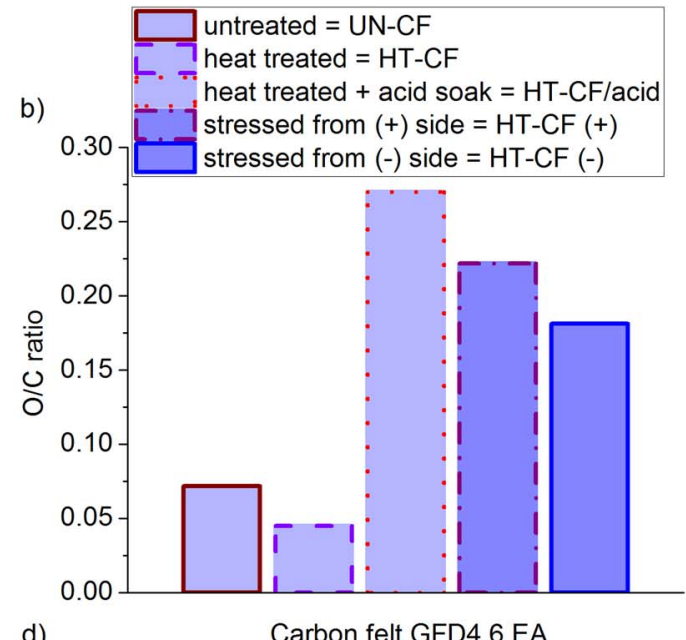

d)

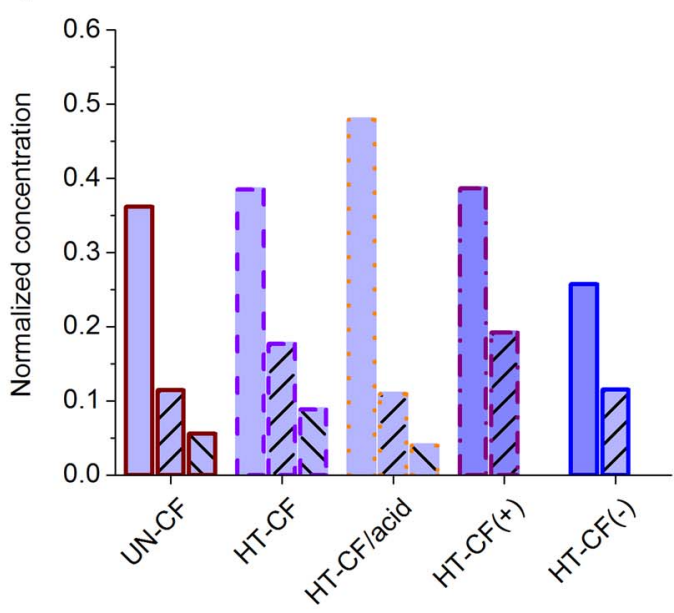

Figure 4. XPS analysis of pristine, heat treated, acid soaked and cycled electrodes showing O/C ratios for a) SGL 39 AA carbon papers (CP) and b) GFD4.6 EA carbon felt (CF) and comparison of different oxygen functional groups for c) SGL 39 AA carbon papers and d) GFD4.6 EA carbon felt.

cycling experiments were investigated by XPS, Raman spectroscopy and SEM.

Electrode characterization before and after cycling.Investigations of surface oxygen functionalities by XPS.-XPS was used to investigate changes in surface oxygen content on the carbon materials before/after heat-treatment and after extended cycling and soaking experiments. Figure 4 shows the changes in total oxygen content $(\mathrm{O} / \mathrm{C})$ and the distribution of different oxygen groups on the carbon materials under investigation.

After heat-treatment, the oxygen content $(\mathrm{O} / \mathrm{C}$ ratio) increased slightly for HT-SGL 39 AA carbon papers from 0.02 to 0.03 (Figure 4a). A slight decrease in $\mathrm{O} / \mathrm{C}$ ratio was observed from 0.075 to 0.05 for HT-GFD4.6 EA carbon felt (Figure 4b). This decrease was also observed by Zhong et al. and explained by the removal of volatile $\mathrm{C}-\mathrm{O}$ contaminants during heat-treatment. ${ }^{35}$ The different behavior upon heat-treatment is an indication that the two materials interact differently with oxygen, this could be related to the different structures of the two pristine materials. The $\mathrm{O} / \mathrm{C}$ ratio after acid soaking increased significantly for both materials, in line with findings by previous authors. ${ }^{26}$ After long term cycling the oxygen content of both cycled materials were compared to the acid-soaked samples as a baseline. A decrease in $\mathrm{O} / \mathrm{C}$ ratio of approximately $33 \%$ was observed for both carbon materials from the negative half-cell. The O/C ratio for HTGFD4.6 EA carbon felt from the positive half-cell showed a slight decrease in $\mathrm{O} / \mathrm{C}$ ratio compared to the acid soaked samples. However, HT-SGL 39 AA carbon papers showed an increase in the O/C ratio after cycling at the positive half-cell.
In both cases the negative electrode showed lower oxygen content after cycling compared to the positive side. It is known that highly oxidizing potentials experienced by the positive electrodes are well in the limit of known electrochemical oxidation of carbon. ${ }^{36}$ Additionally the vanadium ions themselves have also been suggested to induce changes in the oxygen content of carbon electrodes. ${ }^{26}$ The type of oxygen groups is shown in Figures $4 \mathrm{c}$ and $4 \mathrm{~d}$. $\mathrm{C}-\mathrm{OR}, \mathrm{C}=\mathrm{O}$ and $\mathrm{COOH}$ groups were present on the surface of heat treated and acid soaked carbon paper and carbon felt with C-OR groups being the most abundant (see Supplementary Information, Figures S2, S3 and $\mathrm{S} 4)$. After long term cycling experiments, C-OR groups were still the dominant groups on the surface of both materials.

The surface of pristine carbon papers showed a larger amount of higher oxide groups (such as $\mathrm{C}=\mathrm{O}$ and $\mathrm{COOH}$ ) compared to carbon felt. After thermal treatment, the amount of higher oxide groups decreased for carbon papers and increased for carbon felt. Interestingly, in the case of both carbon electrodes, the most oxygen functionalities were introduced onto the surface not as a consequence of thermal treatment but after soaking in $2 \mathrm{M} \mathrm{H}_{2} \mathrm{SO}_{4}$ (see Figures $4 \mathrm{a}$ and $4 \mathrm{~b}$ ). In this case, the bonding nature of the groups introduced was not the same for the two materials. For carbon papers, the amount of higher oxides was reduced after soaking in acid, with $\mathrm{C}=\mathrm{O} / \mathrm{C}-\mathrm{OH}$ ratio decreasing from 0.38 to 0.28 and $\mathrm{COOH} / \mathrm{C}-\mathrm{OH}$ ratio from 0.28 to 0.20 . For carbon felt, a reduction in the concentration of the higher oxide groups $(\mathrm{C}=\mathrm{O}$ and $\mathrm{COOH})$ was also observed, but was more pronounced in this case. The $\mathrm{C}=\mathrm{O} / \mathrm{C}-\mathrm{OH}$ ratio changed from 0.46 to 0.23 and the $\mathrm{COOH} / \mathrm{C}-\mathrm{OH}$ ratio decreased even more from 0.23 to 0.08 . It appears that the presence of $\mathrm{COOH}$ groups relative to 


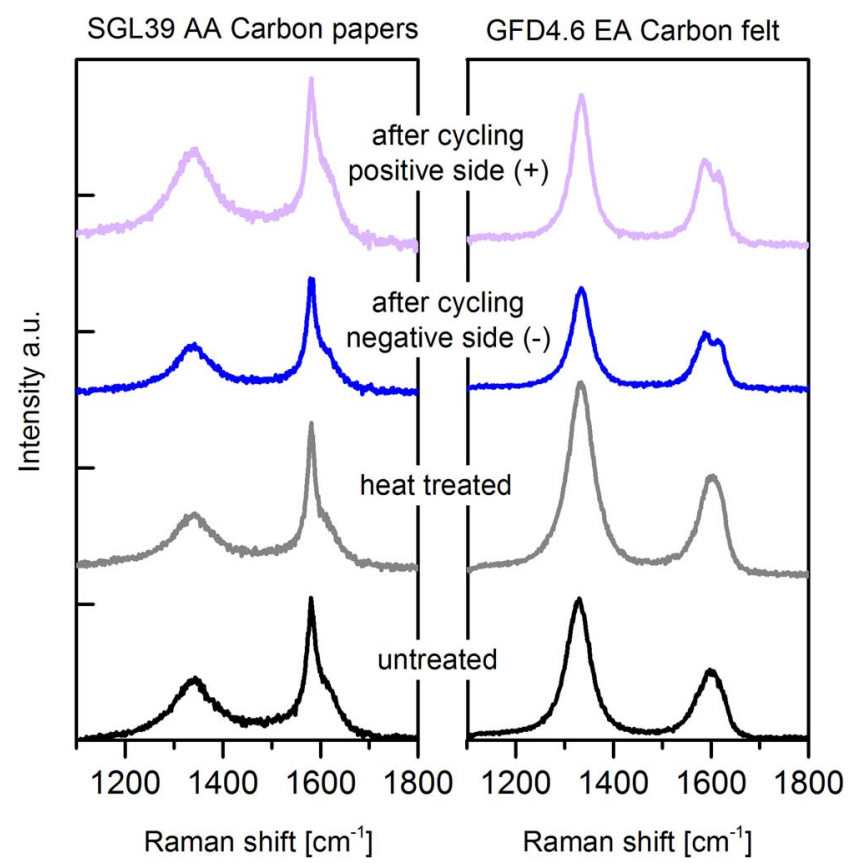

Figure 5. Raman spectra showing SGL 39 AA carbon papers and GFD4.6 EA carbon felt before/after heat-treatment and after cycling the heat treated electrodes at the positive and negative side of the VRB.

$\mathrm{C}-\mathrm{OH}$ groups is much less favored on the surface of carbon felt than on the surface of carbon papers in $2 \mathrm{M} \mathrm{H}_{2} \mathrm{SO}_{4}$ (see Supplementary Information, Table I).

After extended cycling experiments, $\mathrm{COOH}$ groups disappear completely from the surface of carbon felt on both the positive and negative electrodes. The $\mathrm{C}=\mathrm{O} / \mathrm{C}-\mathrm{OH}$ ratio increases from 0.23 to 0.50 and 0.45 for the negative and positive sides respectively. In contrast to this, the amount of $\mathrm{COOH}$ and $\mathrm{C}=\mathrm{O}$ groups relative to $\mathrm{COH}$ groups remains very similar after cycling for carbon papers.

Changes in the amount of oxygen functionalities on the surface of carbon materials and in their bonding nature may occur for a number of different reasons. We have shown here the effect of $2 \mathrm{M}$ sulfuric acid on the amount of surface oxygen functionalities and their bonding nature for two different carbon materials. Vanadium ions have also been shown to influence the amount of oxygen containing functional groups on the surface of carbon electrodes. For instance $\mathrm{V}^{2+}$ and $\mathrm{V}^{3+}$ ions have been reported to reduce the oxygen content on the carbon surface, while $\mathrm{VO}_{2}{ }^{+}$ions have been shown to increase the oxygen content. ${ }^{26}$ Thus the very similar decrease (around $33 \%$ ) in oxygen content observed at the negative electrode for both materials after cycling could be related to the presence of $\mathrm{V}^{2+}$ and $\mathrm{V}^{3+}$ ions. Changes in $\mathrm{O} / \mathrm{C}$ ratio on the surface of electrodes from the positive half-cell (decrease for GFD4.6 EA carbon felt and increase for SGL 39AA carbon papers) may be caused by interactions of both carbon electrodes with $\mathrm{VO}_{2}{ }^{+}$ions. Moreover, exposure to highly positive potentials as well as very negative potentials during cycling can also influence the oxygen content of the surface.

Investigation of carbon materials by Raman spectroscopy and SEM.-The extent of graphitization and amount of defects present in the carbon materials was investigated by Raman spectroscopy. The peaks at $\sim 1350$ (D), 1590 (G) and $1620 \mathrm{~cm}^{-1}$ (D') in the Raman spectrum of carbon can be assigned to the disordered graphitic lattice (edges), the ideal graphitic lattice and disordered graphitic lattice (surface layer) respectively. ${ }^{24,37}$ The Raman spectra of the carbon papers and carbon felt after heat-treatment and extended cycling experiments are shown in Figure 5.

Heat treatment of carbon papers resulted in an increase in the $\mathrm{I}_{\mathrm{D}} / \mathrm{I}_{\mathrm{G}}$ ratio from 0.48 to 0.72 , indicating an increase in the defects at the

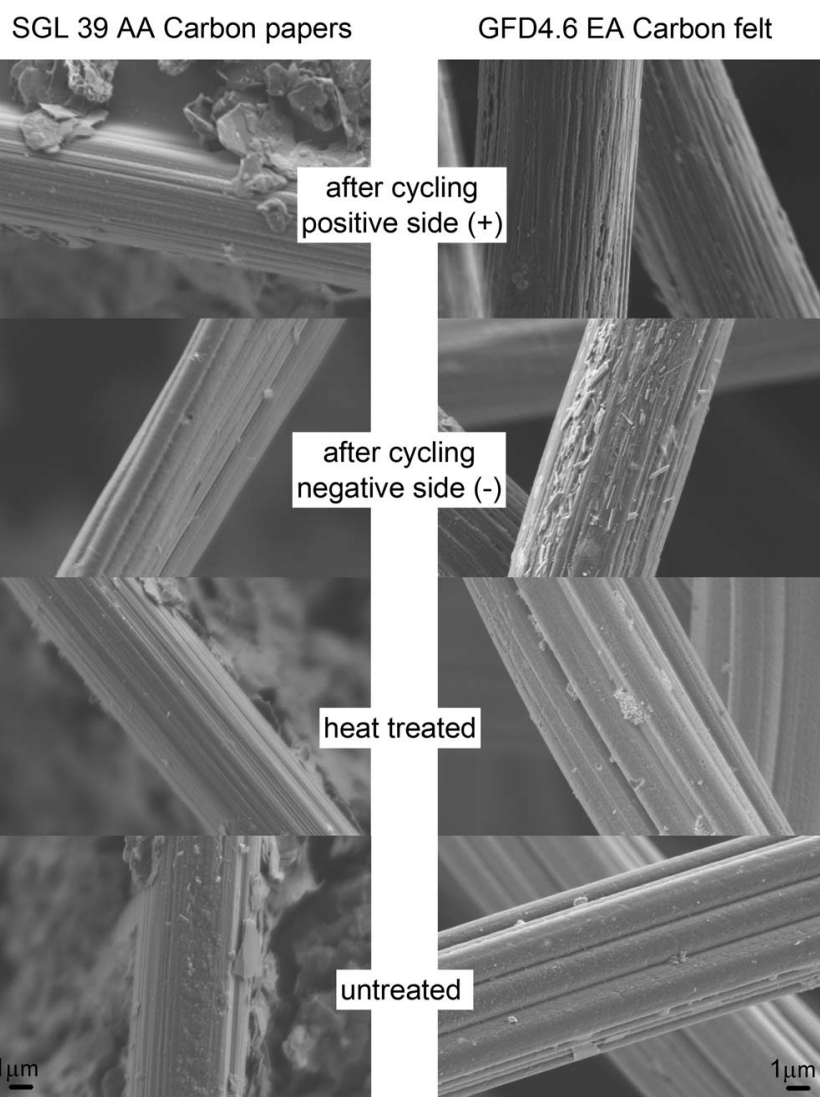

Figure 6. SEM images showing morphological changes of SGL 39 AA carbon papers and GFD4.6 EA carbon felt before/after heat-treatment and after cycling the heat treated electrodes at the positive and negative side of the VRB.

surface of the carbon fibers. XPS revealed the introduction of oxygen functionalities onto the surface of the carbon fibers, which is in line with the increase in defect density observed by Raman spectroscopy. ${ }^{38}$ In contrast to this, heat-treatment of carbon felt resulted in a decrease in the $\mathrm{I}_{\mathrm{D}} / \mathrm{I}_{\mathrm{G}}$ ratio from 1.97 to 1.34 . This decrease in the $\mathrm{I}_{\mathrm{D}} / \mathrm{I}_{\mathrm{G}}$ ratio indicates an increase in the size of graphitic domains in the material after heat-treatment. ${ }^{39}$ XPS in this case showed a decrease in surface oxygen functionalities after heat-treatment, which is in line with the increased degree of graphitization observed by Raman spectroscopy. The effect of extended cycling on both the positive and negative electrodes was examined. It appears that both positive and negative electrodes undergo similar structural changes after cycling. In the case of the HT-SGL 39 AA carbon papers, a further increase in the $\mathrm{I}_{\mathrm{D}} / \mathrm{I}_{\mathrm{G}}$ ratio is observed for both heat treated electrodes after cycling. The corresponding $\mathrm{I}_{\mathrm{D}} / \mathrm{I}_{\mathrm{G}}$ ratios can be found in the Supplementary Information (Figure S5). Again, this can be interpreted as a further increase in disorder and defects (edge sites) at the surface of this material in line with the increase in oxygen functionalities observed by XPS. The HT-GFD4.6 EA carbon felt however sees a further decrease in the $\mathrm{I}_{\mathrm{D}} / \mathrm{I}_{\mathrm{G}}$ ratio after cycling. The appearance of the peak at $1620 \mathrm{~cm}^{-1}$ is notable and is attributed to defects in the graphite lattice at the surface layer and could be linked to the increased oxygen observed after cycling.

Furthermore, the surface morphology was examined by SEM, see Figure 6. Based on the SEM results, the pristine carbon felt and carbon papers differ in the surface appearance of the fibers. The carbon felt has an uneven surface morphology with sharp edge-structures and apparent grooves in the fibers. Carbon papers exhibit a smoother fiber surface with small flakes scattered on the surface. Heat treatment did not cause any visible changes in the morphology of the fibers for both carbon materials. However, after long term cycling HT-GFD4.6 EA 
Table II. Comparison of surface and electrochemical properties of selected heat treated PAN based carbon materials from this study (HT-SGL 39 AA and HT-GFD6.4 EA) and Rayon based carbon felt (GFA6) from a previous study. ${ }^{23}$

\begin{tabular}{|c|c|c|c|}
\hline & $\begin{array}{l}\text { PAN based carbon } \\
\text { papers SGL } 39 \text { AA }\end{array}$ & $\begin{array}{l}\text { PAN based carbon } \\
\text { felt GFD4.6 EA }\end{array}$ & $\begin{array}{l}\text { RAYON based carbon } \\
\text { felt GFA } 6^{\dagger}\end{array}$ \\
\hline cycling stability in $0.8-1.7$ potential window & unstable & stable & unstable \\
\hline period of time in $1.6-1.7 \mathrm{~V}$ potential window & long & short & Long \\
\hline $\mathrm{I}_{\mathrm{D}} / \mathrm{I}_{\mathrm{G}}$ ratio of pristine materials & 0.48 & 1.97 & - \\
\hline
\end{tabular}

carbon felt appears to have a rougher surface morphology compared to the pristine material.

Comparison and overview of different carbon materials.-In order to investigate the influence, if any, of the starting precursor used to synthesize the carbon materials and their performance, the results from this work on two heat treated PAN based carbon materials (HTSGL 39 AA and HT-GFD4.6 EA) were compared with a heat treated Rayon based carbon felt (GFA6) used in a previous study by Derr. et al. ${ }^{23}$ Table II summarizes the key findings.

No correlation between the precursor materials used to synthesize the carbon electrodes and their operational lifespan can be seen. A notable difference between the three carbon materials shown in Table II is their residence times at cell voltages between 1.6-1.7 V during charging. HT-SGL 39 AA carbon papers and Rayon based carbon felt (GFA6) from Derr et al. were exposed to cell potentials above $1.6 \mathrm{~V}$ for a significantly longer period of time during charging compared to the stable HT-GFD4.6EA carbon felt from this study. It follows that the polarization at either or both positive and negative electrodes is greater for these materials, resulting in the higher cell potentials observed during charging. During charging at a fixed current density, the negative half-cell potential is seen to become more negative with time (see Supplementary Information Figure S6). Since the degradation of the carbon papers is observed mainly at the negative electrode side, it can be deduced that more negative potentials at the negative electrode have a detrimental effect on electrode stability. This was confirmed by measurements in which the cutoff cell voltage during charging was reduced from $1.7 \mathrm{~V}$ to $1.6 \mathrm{~V}$. In this case, less performance losses were observed at the negative electrode for HT-SGL 39 AA carbon papers after extended cycling measurements (see Supplementary Information, Figure S7). Thus it appears that the electrode degradation is strongly related to the potential at the negative electrode, particularly during the charging stage.

It has been shown previously that the range of negative potentials experienced by the negative electrode in the VRB fall into a region in which the electrode can be deactivated by reduction. ${ }^{23}$ Oxygen surface groups have been shown to have a positive influence on $\mathrm{V}^{2+} / \mathrm{V}^{3+}$ redox reaction kinetics. However, the stability of oxidized carbon surfaces has also been found to be affected by very negative electrode potentials. ${ }^{20,40,41}$ In this study, XPS analysis revealed that after cycling, the oxygen content at the negative electrode decreased for both carbon materials relative to the acid soaked samples. This decrease in oxygen content could result from exposure to very negative electrode potentials and ultimately contribute to the loss in activity observed at the negative electrode. However, this observation alone does not fully explain the loss in activity observed for the carbon papers and not for carbon felt. Previous studies have suggested that activity losses at the negative electrode could be due to a combination of factors including hydrogen evolution, passivation effects and losses in surface active groups such as oxygen. ${ }^{40-43}$ The two materials in this study differ significantly in their structures, observed by Raman spectroscopy and surface morphology seen by SEM. The structural properties and morphology of the carbon materials could also play a key role in the different stabilities of the carbon materials studied here. It appears that stability and degradation of carbon materials in VRBs is a complex issue. It is likely that a combination of different effects is responsible, including material properties and surface chemistry as is seen in this work. However, other issues such as hydrogen evolution and mass transport also need to be considered in order to gain a full overview of factors contributing to electrode stability and degradation in VRBs.

\section{Conclusions}

A preliminary investigation into performance and electrode stability of selected commercial materials under VRB operating conditions was carried out in this study. Heat treatment was found to be beneficial for cell performance with all materials, HT-SGL 39 AA carbon papers and HT-GFD4.6 EA carbon felt showed the best overall performance. Reference electrode measurements with these two materials revealed that most of the improvements after heat-treatment came from the negative electrode or the $\mathrm{V}^{2+} / \mathrm{V}^{3+}$ side. Upon extended cycling, HTGFD4.6 EA carbon felt was found to be stable and no significant performance losses could be observed. HT-SGL 39 AA carbon papers however showed significant losses in performance which originated primarily from the negative electrode. The degradation of carbon papers at the negative electrode appears to be related to the negative electrode potential itself. Interestingly, even if the cut off voltage limits are the same during the charging process (1.7 V/RHE), unstable carbon papers experience more negative potentials than stable carbon felt over the same charging period.

XPS revealed very similar losses in oxygen at the negative electrode after cycling for both, stable and unstable, carbon electrodes. Losses in surface oxygen could contribute to the losses in activity observed for HT-SGL 39 AA carbon papers, however it does not appear to be the only factor responsible. Raman spectroscopy and SEM revealed significant structural and morphological differences between the two materials with different stability. The formation of different oxygen functional groups upon thermal treatment and acid soaking appears to be influenced by the carbon materials itself and can result in their different cycling stabilities.

The combination of XPS complemented by Raman spectroscopy shown here provides valuable insights into the correlation between structure, surface oxygen functionalities and cycling stability of different carbon electrode materials. These insights will help in the understanding and optimization of a more stable negative electrode material for the VRB system. Further investigations into other possible contributing effects such as mass transport and material structural properties including porosity and morphology are ongoing in our group.

\section{Acknowledgment}

The authors thank the Swiss National Science Foundation (SNF) for their financial support within the REPCOOL project (grant No. $147661)$.

\section{References}

1. G. Kear, A. A. Shah, and F. C. Walsh, Int. J. Energy Res., 36, 1105 (2012).

2. A. Z. Weber, M. M. Mench, J. P. Meyers, P. N. Ross, J. T. Gostick, and Q. Liu, J. Appl. Electrochem., 41, 1137 (2011). 
3. W. Wang, Q. Luo, B. Li, X. Wei, L. Li, and Z. Yang, Adv. Funct. Mater, 23, 970 (2013).

4. K. J. Kim, M. -S. Park, Y. -J. Kim, J. H. Kim, S. X. Dou, and M. Skyllas-Kazacos, J. Mater. Chem., 3, 16913 (2015).

5. W. H. Wang and X. D. Wang, Electrochim. Acta, 52, 6755 (2007),

6. Y. Shao, X. Wang, M. Engelhard, C. Wang, S. Dai, J. Liu, Z. Yang, and Y. Lin, J. Power Sources, 195, 4375 (2010).

7. W. Li, Z. Zhang, Y. Tang, H. Bian, T. W. Ng, W. Zhang, and C. S. Lee, Adv. Sci., 3, 1500276 (2016).

8. H. Q. Zhu, Y. M. Zhang, L. Yue, W. S. Li, G. L. Li, D. Shu, and H. Y. Chen, J. Power Sources, 184, 637 (2008).

9. X. L. Zhou, Y. K. Zeng, X. B. Zhu, L. Wei, and T. S. Zhao, J. Power Sources, 325, 329 (2016)

10. X. L. Zhou, T. S. Zhao, Y. K. Zeng, L. An, and L. Wei, J. Power Sources, 329, 247 (2016).

11. D. Dixon, D. J. Babu, J. Langner, M. Bruns, L. Pfaffmann, A. Bhaskar, J. J. Schneider, F. Scheiba, and H. Ehrenberg, J. Power Sources, 332, 240 (2016).

12. Q. H. Liu, G. M. Grim, A. B. Papandrew, A. Turhan, T. A. Zawodzinski, and M. M. Mench, J. Electrochem. Soc., 159, A1246 (2012).

13. A. M. Pezeshki, J. T. Clement, G. M. Veith, T. A. Zawodzinski, and M. M. Mench, J. Power Sources, 294, 333 (2015).

14. L. Yue, W. Li, F. Sun, L. Zhao, and L. Xing, Carbon, 48, 3079 (2010).

15. L. Wei, T. S. Zhao, G. Zhao, L. An, and L. Zeng, Appl. Energy, 176, 74 (2016).

16. X. G. Li, K. L. Huang, S. Q. Liu, N. Tan, and L. Q. Chen, Trans. Nonferrous Met Soc. China, 17, 195 (2007).

17. K. J. Kim, Y. -J. Kim, J. -H. Kim, and M. -S. Park, Mater. Chem. Phys., 131, 547 (2011).

18. K. J. Kim, S. W. Lee, T. Yim, J. G. Kim, J. W. Choi, J. H. Kim, M. S. Park, and Y. J. Kim, Sci. Rep., 4, 6906 (2014).

19. H. Fink, J. Friedl, and U. Stimming, J. Phys. Chem. C, 120, 15893 (2016)

20. M. A. Miller, A. Bourke, N. Quill, J. S. Wainright, R. P. Lynch, D. N. Buckley, and R. F. Savinell, J. Electrochem. Soc., 163, A2095 (2016).

21. S. M. Taylor, A. Pătru, D. Streich, M. El Kazzi, E. Fabbri, and T. J. Schmidt, Carbon, 109, 472 (2016).

22. E. Agar, C. R. Dennison, K. W. Knehr, and E. C. Kumbur, J. Power Sources, 225, 89 (2013).
23. I. Derr, M. Bruns, J. Langner, A. Fetyan, J. Melke, and C. Roth, J. Power Sources, 325, 351 (2016)

24. J. Langner, M. Bruns, D. Dixon, A. Nefedov, C. Wöll, F. Scheiba, H. Ehrenberg, C. Roth, and J. Melke, J. Power Sources, 321, 210 (2016).

25. I. Derr, A. Fetyan, K. Schutjajew, and C. Roth, Electrochim. Acta, 224, 9 (2017).

26. A. M. Pezeshki, R. L. Sacci, G. M. Veith, T. A. Zawodzinski, and M. M. Mench, $J$. Electrochem. Soc., 163, A5202 (2015).

27. O. Nibel, T. J. Schmidt, and L. Gubler, J. Electrochem. Soc., 163, A2563 (2016).

28. D. S. Aaron, Q. Liu, Z. Tang, G. M. Grim, A. B. Papandrew, A. Turhan, T. A. Zawodzinski, and M. M. Mench, J. Power Sources, 206, 450 (2012).

29. Y. A. Gandomi, D. S. Aaron, T. A. Zawodzinski, and M. M. Mench, J. Electrochem. Soc., 163, A5188 (2015)

30. A. Kiiver, I. Vogel, and W. Vielstich, J. Power Sources, 52, 77 (1994).

31. X. Ren, T. E. Springer, and S. Gottesfeld, J. Electrochem. Soc., 147, 92 (2000).

32. X. Li, H. Zhang, Z. Mai, H. Zhang, and I. Vankelecom, Energy Environ. Sci., 4, 1147 (2011).

33. D. Yang, A. Velamakanni, G. Bozoklu, S. Park, M. Stoller, R. D. Piner, S. Stankovich, I. Jung, D. A. Field, C. A. Ventrice, and R. S. Ruoff, Carbon, 47, 145 (2009).

34. G. Ilangovan and K. C. Pillai, Langmuir, 13, 566 (1997).

35. S. Zhong, C. Padeste, M. Kazacos, and M. Skyllas-Kazacos, J. Power Sources, 45, 29 (1993)

36. K. Kinoshita, Carbon Electrochemical and Physiochemical Properties, Wiley\&Sons, Toronto (1988).

37. A. Sadezky, H. Muckenhuber, H. Grothe, R. Niessner, and U. Pöschl, Carbon, 43, 1731 (2005).

38. P. Han, H. Wang, Z. Liu, X. Chen, W. Ma, J. Yao, Y. Zhu, and G. Cui, Carbon, 49, 693 (2011).

39. F. Tuinstra, J. Chem. Phys., 53, 1126 (1970)

40. A. Bourke, M. A. Miller, R. P. Lynch, X. Gao, J. Landon, J. S. Wainright, R. F. Savinell, and D. N. Buckley, J. Electrochem. Soc., 163, A5097 (2015).

41. S. M. Taylor, A. Pătru, E. Fabbri, and T. J. Schmidt, Electrochem. Commun., 75, 13 (2017).

42. R. Schweiss, A. Pritzl, and C. Meiser, J. Electrochem. Soc., 163, A2089 (2016).

43. S. Rudolph, U. Schröder, and I. M. Bayanov, J. Electroanal. Chem., 703, 29 (2013) 